\title{
FROM THE INSIDE
}

\section{There's more to medicine than machines}

\author{
Elizabeth F. Maringer, Jay Shiland and Daniel Brodie*
}

C 2018 Springer-Verlag GmbH Germany, part of Springer Nature and ESICM

After $24 \mathrm{~h}$ in the emergency room (ER), my first reaction when the doctor said they finally had an intensive care unit (ICU) bed was relief. I didn't know enough (or wasn't thinking clearly enough) to fully appreciate what that meant. We arrived at the ER on a Sunday night, with Jay battling what turned out to be "impressive" pneumonia in both lungs. I had walked by a group of ER doctors huddled around an X-ray that was all white. I didn't realize until later that it was Jay's.

When the ER doctor called for an ICU consult, it didn't register to be afraid. Even as Jay was wheeled into the ICU, I looked around and again didn't appreciate the gravity of the situation. Which, in retrospect, is completely insane. Even then, my ignorance (and perhaps denial) prevented me from seeing the cliff ahead. Maybe it was my brain's way of managing the overwhelming stress of the situation. To somehow make it tolerable so that I could function. And make decisions. And sign forms. And not fall apart.

To a lay person, ICU patients look like science experiments-immobile and hooked up to so many beeping machines. Not actually human beings. Jay went into the ICU on a Monday. By Tuesday, he was one of those experiments-sedated, intubated, and on a vent. And that was just the beginning. Over the next 2 weeks, he developed severe acute respiratory distress syndrome (ARDS) that only worsened. The doctors explained that he was likely to die, and that his only chance was something called extracorporeal membrane oxygenation (ECMO). I had never heard of ECMO.

When the Columbia doctors came to put Jay on ECMO and bring him back to their ICU, I didn't immediately consent. It sounded so extreme, and I had so many questions. After hours of cross-examining them, I finally

\footnotetext{
*Correspondence: hdb5@cumc.columbia.edu

Department of Medicine, Division of Pulmonary, Allergy and Critical Care Medicine, Columbia University College of Physicians and Surgeons/New York-Presbyterian Hospital, 630 West 168th Street, Ph8 East Room 101, New York, NY 10032, USA
}

realized that choice was an illusion. Jay had no other options. He spent the next 10 days on ECMO, and then many additional weeks recovering and in acute rehab.

To the family of someone who is critically ill, the ICU feels like you have entered an alternative universe. Time feels suspended because the lights are always on and the machines are always beeping. There is no day and night which, when added to the fact that your perfectly healthy 41-year-old husband is now on the brink of death, causes a feeling of disorientation. It was shocking to see him in that place and in that condition. I refused to let anyone see Jay on ECMO because I did not want that image forever in their minds. Our children didn't see him for 7 weeks until he was in rehab and the tracheostomy was out. And I hunkered down and focused every ounce of energy on Jay. My world shrank, and I became hypervigilant. Everything outside of the ICU felt surreal. I would look at people going about their lives and think that they could not possibly appreciate what was happening on the fourth floor.

I learned every machine and every number. I asked a million questions and, I am quite sure, was not the easiest person to deal with. I learned how an ICU works, how important the nurses are, how the ICU fellows are your lifeline. You become dependent on each and every person taking care of your husband, and you hang on their every word. I learned to always have someone with me when speaking with doctors because everyone hears something different. I also learned how important it is for a patient to have a loved one there at all times, reminding everyone that this is a person and not just a "case". Every time a new doctor came along-and there were many-I made sure he or she knew that Jay was 41 with two young children at home.

Perhaps most importantly, I learned that medicine is as much an art as a science. I kept asking questions that I felt should have answers. But there aren't always answers. Sometimes doctors do what they think or hope will work, but aren't sure. They adjust and readjust settings on the 
vent. They try a different antibiotic. They wheel in the canister of nitric oxide. Or put someone on ECMO even if, at the time, other well-respected doctors think they are crazy.

All around us, patients died, which is tough for the family of an ICU patient. After one particularly bad scene next door, I couldn't take it and left the ICU. The attending saw and later found me just to reassure me that they were doing everything they could for Jay. I became superstitious, and refused to go into the room designated for private conversations. To me, that was the room where they tell you that your husband is going to die, so I preferred to have all my conversations in the hall. And, during a particularly stressful time before ECMO, I made the fellow promise that she would tell me if we were having "the talk" so that I was clear about what was being said. More than once, I asked "is this the talk? Are we having that discussion?" Thankfully, her answer was always "no," and I trusted her promise to always be honest with me.

Ultimately, what got me through the 9 weeks of Jay's hospitalization was the compassion that everyone showed not just to Jay but also to me. Patients and families are utterly dependent on caregivers. We become attached to them. For us, many of Jay's doctors have become part of our family. We feel that they are the only ones who truly understand what we went through. They know how bad it was because they were there. When Jay came off ECMO and turned the corner, they shared our relief and joy. And now, when we go back to the ICU to visit, they cry because he walks in wearing his suit, looking as if nothing had ever happened. And for that, we love them.

\section{Abbreviations}

ER: Emergency room; ICU: Intensive care unit; ECMO: Extracorporeal membrane oxygenation.

\section{Compliance with ethical standards}

\section{Conflicts of interest}

Dr. Brodie is currently the co-chair of the Trial Steering Committee for the VENT-AVOID trial sponsored by ALung Technologies; he was previously on the medical advisory board of ALung Technologies and Kadence (Johnson \& Johnson). All compensation for these activities is paid to Columbia University.

Received: 26 February 2017 Accepted: 1 March 2018

Published online: 12 March 2018 